\title{
HABITUAL PHYSICAL ACTIVITY PATTERN AND ITS ASSOCIATION WITH GENDER AND BODY COMPOSITION IN HEALTHY ADULTS
}

\author{
Rudīte Lagzdina, Maija Rumaka \\ Department of Human Physiology and Biochemistry, Rīga Stradiņš University, Riga, \\ Latvia
}

\begin{abstract}
An appropriate level of physical activity (PA) is beneficial for health and weight management. This study examines the relationship of habitual PA and activity energy expenditure (AEE) in a typical week with gender and body composition parameters. Data of habitual PA of 72 healthy adults were collected with the heart rate and motion sensor (Actiheart). Total and segmental body fat was measured with bioelectrical impedance analyser. Men were more active in total and on working days and had shorter light and longer moderate and vigorous PA on working days than females $(\mathrm{p}<0.05)$. Females had less inactive and sitting time on days off. Inactive and sitting time in working days for both genders correlated positively with visceral fat rating, body and leg fat $\%(\mathrm{p}<0.05)$. In male's duration of working days' moderate PA correlated inversely, but light PA positively with these parameters $(\mathrm{p}<0.05)$. Males with more vigorous PA in working day and AEE in days off had lower body fat $\%(\mathrm{p}<0.05)$. A distinctive PA pattern on working days and days off indicates a gender-related differences. Decrease of time of inactivity and light PA and increase of duration of moderate and vigorous PA was associated with lower body and segmental fat amount.
\end{abstract}

Keywords: physical activity, gender, body composition, healthy adults, energy expenditure

\section{INTRODUCTION}

Having an appropriate level of physical activity (PA) is beneficial for all age groups. However, the type and volume of recommended health-enhancing PA can have both individual and goal-dependent differences [20]. 
An adequate amount of PA in adults improves cardiorespiratory fitness, metabolic and bone health and reduces risks of breast and colon cancer and depression [30]. Any increase of PA level in inactive persons is associated with a positive health effect and decreases risks of non-communicable diseases and premature death [18]. PA is strongly suggested for maintenance of normal body weight, fat amount and is necessary to reduce the excess visceral and subcutaneous fat of the upper body, which has strong association with metabolic syndrome $[12,26]$. Physical inactivity is defined as the fourth leading cause of death in the world [15]. The health risks caused by physical inactivity are similar to those attributable to smoking or obesity. In addition to leisure time, domestic and transport-related activities, daily physical activities substantially depend on occupational PA. Many people in urban areas are employed in professions with negligible PA, which can be considered a potential risk factor for decreased total daily PA resulting in positive energy imbalance.

A decreased level of PA in healthy individuals can be attributed to the lack of sufficient amount of moderate and vigorous PA and by a long time spent in a sitting or reclining posture (called sedentary behaviour). Current evidence justifies considering a lack of $\mathrm{PA}$ as a distinct factor in health risks $[10,14]$.

A number of tools are available to assess PA and to characterize its various components. Large-scale studies use mostly self-reported questionnaires that allow for the collection of relatively inexpensive but potentially biased data, whereas device-based trials enable more accurate and detailed data acquisition.

Individually worn devices usually collect real-time stamped data of predefined physiological parameters (such as body acceleration, heart rate (HR), body temperature, and galvanic skin response), which are analysed with validated algorithms allowing researchers to estimate the intensity and duration of performed activity, to describe the pattern of PA during the wearing time and to calculate energy expenditure details.

Bioelectrical impedance analysis (BIA) is a widely used method for examination of body composition in epidemiological and clinical studies. Total lean and fat mass and their segmental distribution can be determined with high accuracy in healthy, young, euvolemic adults especially if multifrequency BIA device models are used and recommended measurement conditions are considered $[5,16]$.

Data of PA and body composition provide relevant and accurate information to be considered in identifying actual situations and counselling for 
targeted actions on required changes in PA and energy expenditure for both the individual and group levels.

This cross-sectional study was designed to evaluate the pattern of PA, total energy expenditure (TEE) and activity energy expenditure (AEE) in free-living conditions in a typical week and to assess relationship of routine PA with gender and body composition parameters in healthy adults.

\section{MATERIALS AND METHODS}

\section{Subjects}

This study enrolled 97 adult volunteers of both genders, with the following inclusion criteria: apparently healthy individuals aged between 20 and 50 years, not using any medication during participation in the study, and engaged in typical occupational routines (e.g., not during the annual holiday or leave). The recruitment of participants occurred using a chain-referral sampling technique. The study was approved by the Ethics Committee of Riga Stradinš University, and informed consent was signed by each participant upon the entry to the study.

\section{Procedures}

Body weight and height of the participants were measured (to the nearest $0.01 \mathrm{~kg}$ and $1.0 \mathrm{~cm}$, respectively). Participants were asked to characterize the type of their occupational duties depending on the volume of physical work involved. Due to variety in occupational duties, two groups for analysis were created. Group I included persons with sitting and light PA at work (mainly office workers), whereas group II consisted of participants who had moderate to vigorous $\mathrm{PA}$ at work.

A combined HR and motion sensor, Actiheart (CamNtech Ltd, Papworth Everard, UK), was used for PA and energy expenditure measurement. Participants were familiarized with the use of the Actiheart device and instructed to wear it continuously over consecutive days, with the exception of waterbased activities (e.g., bathing, swimming). The minimum requested time for wearing the device was at least two full working days and one full day off, but participants were advised to wear the device longer if possible, to collect additional days of data, enabling error-free, quality data recording.

Before attachment, the Actiheart device was prepared by inputting subjects' date of birth, weight and height, and the 15-s data recording mode was started immediately. The device was affixed to the participant's chest at one 
of the manufacturer's proposed locations with ECG electrodes designed for long-term monitoring [2].

Body fat percent, visceral fat rating, fat and lean mass of participants were determined with a multi-frequency bioelectrical impedance body composition analyser MC-180MA according to manufacturer's instruction (Tanita, Japan). Participants were asked to stand with bare feet on the electrode panel and hold electrodes in both hands with arms hanging down naturally. To obtain more precise results, participants were measured in the morning, after overnight fasting with the limited physical activity level before the test. Additionally, in bioimpedance measurements fat and muscle mass in five segments - trunk, right and left arm and right and left leg were determined. Body mass index, fat percent in each extremity and trunk were calculated.

After the wearing period, Actiheart data were downloaded and analysed with the Actiheart Software, version 4.0.116. In every recorded file, lost or corrupt HR signals were removed and replaced by applying a cleaning algorithm from the manufacturer's software. Both signals, HR and acceleration counts, were necessary for the energy expenditure calculation. Therefore, the obtained data were considered valid for subsequent analysis only if those recordings indicated that the wearing time was two or more working days and one day off and only if the HR signal was registered for at least $60 \%$ of each day (864 min total) [3].

Daily AEE was calculated by the software using a Branched Equation Group Cal JAP2007 energy model. This model interprets simultaneous HR and accelerometery data and is suggested for the most accurate AEE estimation in free-living conditions [24].

To ensure precise analysis of the data of each study participant, a calibration of the data registered by Actiheart was performed by considering the participant's individual resting value in accordance with his/her daily sleeping HR. The resting metabolic rate (RMR) was calculated using Schofield's equation for respective gender and age. The result of TEE was derived as a sum of RMR and AEE. Ten percent of the sum was added as a food thermogenic effect. The energy expenditure values from registered days were used to calculate TEE and RMR ratio - PA level (PAL), which was assessed according to WHO guidelines [9]. Since there was tendency of PA to variate between working days and days off, for calculation purposes of the average MET minutes and energy expenditure results from the working days and day off were taken in a proportion of 5:2, according to proportion of working days and days off in a regular week.

After evaluation of the recorded data, 24 participants who did not have sufficient error-free recorded time on their Actiheart devices were excluded 
from further analysis. Initial analysis of the Actiheart data revealed the results of one female participant as an outlier due to unusually high energy expenditure values on the day off. Therefore, these data were not accepted as valid. The remaining data for 72 subjects were included in the analysis.

The full data set of Actiheart files was exported to MS Excel (Microsoft Corporation, USA), and recordings for each day were sorted into four groups of standard metabolic equivalent of task (MET) ranges. Minutes in the range 1.0-2.9 MET represent the duration of light activities, 3.0-6.0 MET minutes indicate moderate activity, and $\geq 6.1$ MET represents vigorous physical activities [3]. Time corresponding to activity level 1.0-1.5 MET was given separately. Although Actiheart registers body motion as activity, the manufacturer does not provide an exact cut-off point for counts per minute to define sitting activity and to distinguish it from sleeping. For this reason, the activity level of 1.0-1.5 MET was considered to include a combination of sleeping time and awake time with minimal, most likely sedentary, activity (further named as inactive and sitting time) [22].

\section{Statistical analysis}

Statistical analysis was performed using SPSS Statistics v. 22.0 (IBM Corporation, USA) with significance set at $\mathrm{p}<0.05$. The analysis included descriptive statistics for the whole sample and was stratified by gender in all cases. The results are presented as the mean value with standard deviation or median with interquartile range. Parameter differences between genders and between working days and days off were assessed using an independentsamples t-test when there was a Gaussian distribution and Mann-Whitney test for non-Gaussian data distributions. The correlation of PAL, energy expenditure, duration of the light, moderate and vigorous PA domains with body composition parameters was determined by Spearman's correlation test. Association of PAL with MET minutes of moderate and vigorous activities was described using regression analysis.

\section{RESULTS}

The study sample that was valid for analysis consisted of 72 participants and contained more women (51\%) than men. The anthropometric characteristics of the participants are presented in Table 1. Mean age in both genders was similar, but height, body mass, and BMI were significantly higher, and body fat $\%$ lower in the male group ( $\mathrm{p}<0.05)$. For $74.3 \%$ of males and $67.8 \%$ of females body fat $\%$ was normal, but $11.4 \%$ males and $29.7 \%$ of females 
were classified as underfat, and $14.3 \%$ and $2.7 \%$ as overfat, respectively [11]. Visceral fat rating in all participants was in normal range according to the scale provided by manufacturer [13].

Table 1. Descriptive characteristics of the study participants

\begin{tabular}{lcc}
\hline & $\begin{array}{c}\text { Men }(\mathrm{n}=35) \\
\text { Mean } \pm \text { SD }\end{array}$ & $\begin{array}{c}\text { Women }(\mathrm{n}=37) \\
\text { Mean } \pm \text { SD }\end{array}$ \\
\hline Age (years) & $30.8 \pm 5.6$ & $29.3 \pm 5.0$ \\
\hline Height $(\mathrm{cm})$ & $184 \pm 7$ & $169 \pm 5$ \\
\hline Body mass $(\mathrm{kg})$ & $79.95 \pm 9.79$ & $62.56 \pm 7.07$ \\
\hline BMl $\left(\mathrm{kg} / \mathrm{m}^{2}\right)$ & $23.7 \pm 2.4$ & $22.0 \pm 2.5$ \\
\hline Body fat $(\%)$ & $14.2 \pm 5.1$ & $23.8 \pm 5.1$ \\
\hline
\end{tabular}

Summary data of energy expenditure are presented in Table 2. Results representing a working day are given as an average value calculated from both registered days. Calculated metabolic rates per kilogram of body mass (e.g. RMR, TEE and AEE) on working days were lower in women. No differences in energy expenditure parameters were found during days off.

Table 2. Characteristics of energy expenditure registered by the Actiheart

\begin{tabular}{lccc}
\hline & $\begin{array}{c}\text { Men } \\
(\mathbf{n}=35) \\
\text { Mean } \pm \text { SD }\end{array}$ & $\begin{array}{c}\text { Women }(\mathbf{n}=37) \\
\text { Mean } \pm \text { SD }\end{array}$ & p-value $^{1}$ \\
\hline RMR per $\mathrm{kg}(\mathrm{kcal} / \mathrm{kg} / \mathrm{day})$ & $23.6 \pm 1.7$ & $22.5 \pm 1.3$ & 0.002 \\
\hline TEE on working day per $\mathrm{kg}(\mathrm{kcal} / \mathrm{kg} / \mathrm{day})$ & $45.2 \pm 9.7$ & $39.5 \pm 5.2$ & 0.003 \\
\hline AEE on working day per $\mathrm{kg}(\mathrm{kcal} / \mathrm{kg} /$ day) & $17.1 \pm 7.8$ & $13.1 \pm 4.2$ & 0.009 \\
\hline TEE on day off per $\mathrm{kg}(\mathrm{kcal} / \mathrm{kg} / \mathrm{day})$ & $44.4 \pm 9.7$ & $42.0 \pm 5.8$ & 0.216 \\
\hline AEE on day off per $\mathrm{kg}(\mathrm{kcal} / \mathrm{kg} /$ day) & $16.8 \pm 7.9$ & $15.4 \pm 5.0$ & 0.378 \\
\hline
\end{tabular}

${ }^{1} p$-value shows gender differences, comparisons performed by independent samples t-test.

A comparison of the minutes in each MET group for men and women are presented in Figure 1. A comparison between genders revealed that men had statistically fewer minutes of 1.0-2.9 MET activities and more 3.0-6.0 and $\geq 6.1$ MET minutes on working days than women did, whereas women had statistically fewer minutes of 1.0-1.5 MET activities than men did on their day off. 

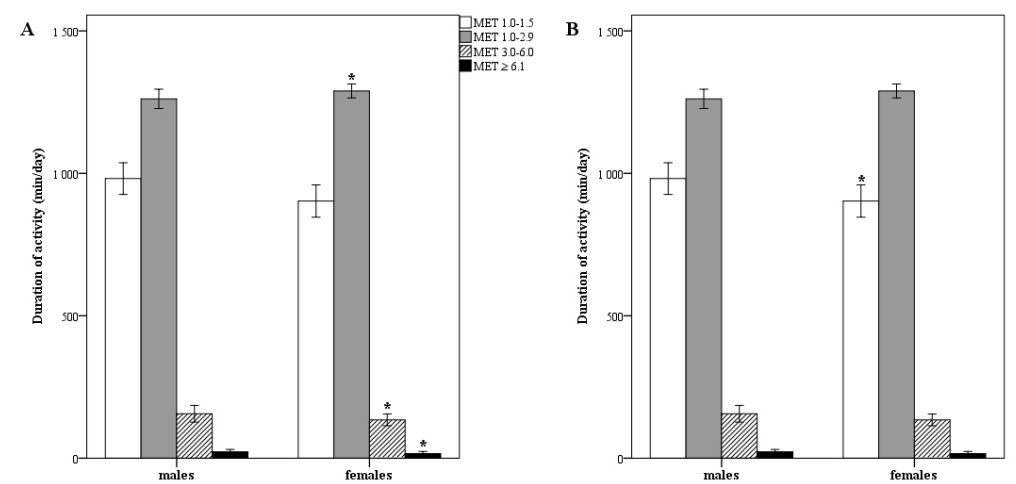

Figure 1. Mean number of minutes corresponding to 1.0-1.5 MET, 1.0-2.9 MET, 3.06.0 MET and $\geq 6.1$ MET physical activities with $95 \% \mathrm{Cl}$ in working day $(\mathrm{A})$ and day off (B). ${ }^{*} p<0.05$ vs. respective parameter in males from the Mann-Whitney test

In the male group, the activity values were similar between the working day and day off. Female participants had fewer minutes of low activity (1.0-1.5 and 1.0-2.9 MET) and more minutes of moderate activity during their day off comparing to working days (Table 3 ).

Table 3. Comparison of working day and day off PA registered by the Actiheart

\begin{tabular}{|c|c|c|c|}
\hline & $\begin{array}{l}\text { On working day } \\
\text { Median [IQR] }\end{array}$ & $\begin{array}{l}\text { On day off } \\
\text { Median [IQR] }\end{array}$ & p-value ${ }^{1}$ \\
\hline \multicolumn{4}{|c|}{ Minutes of 1.0-1.5 MET (min/day) } \\
\hline men & 1006 [853-1088] & 1013[874-1104] & 0.987 \\
\hline women & 966 [905-1063] & 888 [808-1011] & 0.023 \\
\hline \multicolumn{4}{|c|}{ Minutes of 1.0-2.9 MET (min/day) } \\
\hline men & 1277 [1214-1329] & 1283 [1232-1341] & 0.492 \\
\hline women & 1319 [1284-1357] & 1306 [1229-1348] & 0.030 \\
\hline \multicolumn{4}{|c|}{ Minutes of 3.0-6.0 MET (min/day) } \\
\hline men & 123 [97-170] & 132 [93-190] & 0.295 \\
\hline women & 111 [77-137] & 126 [80-184] & 0.028 \\
\hline \multicolumn{4}{|c|}{ Minutes of $\geq 6.1 \mathrm{MET}$ (min/day) } \\
\hline men & 13 [4-39] & $16[1-37]$ & 0.787 \\
\hline women & $7[2-16]$ & $7[1-28]$ & 0.239 \\
\hline
\end{tabular}

${ }^{1} p$-value shows working day and day off differences in each gender, comparisons performed by Wilcoxon signed rank test. 
Based on calculated PAL, three groups were created: low active with a PAL less than 1.69, moderate active with a PAL 1.70 to 1.99 and the highly active group with a PAL greater than or equal to 2.00 [18]. According to the results from the average PAL, $28.6 \%$ of males and $29.7 \%$ of females were defined as low active, $28.6 \%$ of males and $54.1 \%$ of females were defined as moderate active, and the PAL of $42.9 \%$ of males and $16.2 \%$ of females indicated a high activity level.

A strong correlation between average PAL and time in 3.0-6.0 MET activities was found (Spearman's rho in $\operatorname{men}=0.861$, in women $=0.875$, $\mathrm{p}<0.01)$. This type of activity explains $69 \%$ of the PAL results in men and $82 \%$ in women. The correlation of PAL and $\geq 6.1$ MET activities was strong in the men's group (Spearman's rho $=0.802, \mathrm{p}<0.01$ ) and moderate in women (Spearman's rho $=0.485, \mathrm{p}<0.01$ ), determining $50 \%$ of PAL in men and $34 \%$ in women (Figure 2.).
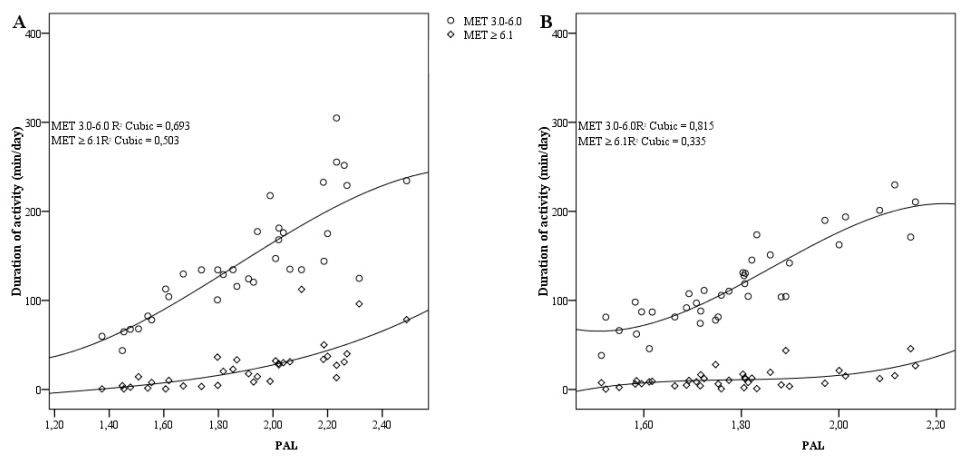

Figure 2. Association of average PAL and duration of activities corresponding to 3.06.0 MET and $\geq 6.1$ MET in males (A) in females (B).

Comparisons of PAL, AEE, TEE and the time of activities corresponding to $1.0-1.5,1.0-2.9,3.0-6.0$ and $\geq 6.1$ MET in both occupational groups were performed. None of the results showed significant differences $(\mathrm{p}>0.05)$.

Statistically significant correlation coefficients between PA parameters and BMI, visceral fat rating and body fat $\%$ are shown in Table 4 . In males inactive and sitting time and duration of light activities in a working day correlated positively with BMI, visceral fat rating, and body fat \%, while duration of moderate activities correlated negatively with these parameters. Duration of vigorous activities had negative association with body fat $\%$ only. Average and working day AEE had negative associations with BMI, visceral fat rating, body fat \%, but day off AEE had negative correlations only with the body fat \%. In females inactive and sitting time in working days 
had positive correlation with visceral fat rating and body fat \%, but average and working day AEE correlated negatively with these parameters of body composition.

Table 4. Correlation coefficients between physical activity and body composition parameters $^{1}$

\section{BMI Visceral fat rating Body fat \%}

Minutes of 1.0-1.5 MET on working day

\begin{tabular}{|c|c|c|c|}
\hline men & 0.455 & 0.430 & 0.378 \\
\hline women & - & 0.438 & 0.341 \\
\hline \multicolumn{4}{|c|}{ Minutes of 1.0-2.9 MET on working day } \\
\hline men & 0.437 & 0.401 & 0.477 \\
\hline women & - & - & - \\
\hline \multicolumn{4}{|c|}{ Minutes of 3.0-6.0 MET on working day } \\
\hline men & -0.408 & -0.451 & -0.364 \\
\hline women & - & - & - \\
\hline \multicolumn{4}{|c|}{ Minutes of $\geq 6.1$ MET on working day } \\
\hline men & - & - & -0.359 \\
\hline women & - & - & - \\
\hline \multicolumn{4}{|c|}{ AEE on working day per kg } \\
\hline men & -0.510 & -0.498 & -0.574 \\
\hline women & - & -0.485 & -0.362 \\
\hline \multicolumn{4}{|c|}{ AEE on day off per kg } \\
\hline men & - & - & -0.351 \\
\hline women & - & - & - \\
\hline \multicolumn{4}{|c|}{ Average AEE per kg } \\
\hline men & -0.450 & -0.482 & -0.601 \\
\hline women & - & -0.500 & -0.364 \\
\hline
\end{tabular}

${ }^{1}$ only Spearman correlation coefficients for which $\mathrm{p}<0.05$ are presented.

Statistically significant correlation coefficients between PA parameters and segmental fat $\%$ are shown in Table 5. In males inactive and sitting time and duration of light activities in a working day correlated positively with body 
fat $\%$ in both legs and duration of light activities additionally - with the trunk fat $\%$. There were negative correlations between duration of moderate activities in working day and body fat \% in legs, and between duration of vigorous activities in a working day and trunk and left leg fat $\%$. Average and working day AEE had negative associations with all segmental body fat \%, but day off AEE had negative correlations only with left leg fat $\%$.

Table 5. Correlation coefficients between physical activity and segmental fat percents ${ }^{1}$

\begin{tabular}{|c|c|c|c|c|c|}
\hline & $\begin{array}{c}\text { Fat } \% \text { in } \\
\text { trunk }\end{array}$ & $\begin{array}{l}\text { Fat \% in } \\
\text { left arm }\end{array}$ & $\begin{array}{l}\text { Fat } \% \text { in } \\
\text { right arm }\end{array}$ & $\begin{array}{l}\text { Fat } \% \text { in } \\
\text { left leg }\end{array}$ & $\begin{array}{l}\text { Fat \% in } \\
\text { right leg }\end{array}$ \\
\hline \multicolumn{6}{|c|}{ Minutes of 1.0-1.5 MET on working day } \\
\hline men & - & - & - & 0.500 & 0.436 \\
\hline women & - & - & - & 0.497 & 0.448 \\
\hline \multicolumn{6}{|c|}{ Minutes of 1.0-2.9 MET on working day } \\
\hline men & 0.427 & - & - & 0.554 & 0.450 \\
\hline women & - & - & - & - & - \\
\hline \multicolumn{6}{|c|}{ Minutes of 3.0-6.0 MET on working day } \\
\hline men & - & - & - & -0.464 & -0.405 \\
\hline women & - & - & - & - & - \\
\hline \multicolumn{6}{|c|}{ Minutes of $\geq 6.1$ MET on working day } \\
\hline men & -0.336 & - & - & -0.383 & \\
\hline women & - & - & - & - & \\
\hline \multicolumn{6}{|c|}{ AEE on working day per kg } \\
\hline men & -0.522 & -0.408 & -0.484 & -0.661 & -0.563 \\
\hline women & -0.355 & - & - & -0.516 & -0.485 \\
\hline \multicolumn{6}{|c|}{ AEE on day off per kg } \\
\hline men & - & - & - & -0.339 & - \\
\hline women & - & - & - & - & - \\
\hline \multicolumn{6}{|c|}{ Average AEE per kg } \\
\hline men & -0.551 & -0.449 & -0.505 & -0.655 & -0.551 \\
\hline women & -0.350 & - & - & -0.485 & -0.435 \\
\hline
\end{tabular}

${ }^{1}$ only Spearman correlation coefficients for which $\mathrm{p}<0.05$ are presented. 
Inactive and sitting time in working days in females had positive correlations with segmental fat $\%$ in legs. Average and working day AEE had negative associations only with leg fat \%. Both genders did not have any significant correlations between duration of different activities in a day off and body composition parameters. Day off AEE had negative correlations with fat $\%$ in trunk only for males, but females did not have any correlations with day off AEE either.

\section{DISCUSSION}

Data obtained by Actiheart revealed that male participants had fewer minutes of low activity (1.0-2.9 MET) and more time of moderate (3.06.0 MET) and vigorous ( $\geq 6.1 \mathrm{MET})$ PA than females during working days. This pattern of activity leads to higher AEE and TEE per body mass kilogram. The day off results revealed higher inactive and sitting (1.0-1.5 MET) minutes in males than in females, which eliminates the gender difference in AEE on the day off. Working day PA consists of occupational and non-occupational activities. A similar number of males and females described their occupation as involving moderate and vigorous PA. However, in the same occupational group, the heavier effort of males cannot be ignored. Additionally, moderate to vigorous non-occupational activities with the tendency to perform the muscle strengthening forms of exercises [8] might be more common in males. This could be partially explained by the fact that enjoyment is the motivational factor to stimulate greater intensity PA in males [25]. In men, there were no significant differences in PA pattern between the working days and day off, whereas women had a decrease in low intensity activity but an increase in moderate activity time during their day off.

The activity increases for women during the day off may be due to household or leisure time activities, as observed by studies in other populations $[6,19]$. These gender differences in lifestyle might be used to design genderspecific interventions to increase PA level in adults.

Since men have more moderate and vigorous activity during working days, a higher proportion of men than women were qualified as highly active (43\% vs.16\%) according to PAL. However, health-related (moderate and high) activity was reached by a similar number of participants of both gender groups.

The value of PAL is determined by the duration of time spent engaged in moderate and vigorous PA. The main PAL variation in both genders was explained by time spent in moderate activities. Activities of $\geq 6.1 \mathrm{MET}$ determined less variation in PAL, however, this had greater influence in the male 
group due to a longer amount of time engaged in daily vigorous PA than was found in the female group.

Men who had lesser inactive and sitting time and duration of light activities, and more time spent in moderate activities on working days had lower BMI, visceral fat rating, body fat $\%$, and fat percent in both legs. High intensity activities (MET 6.1 and more) led to decrease of body, trunk and left leg fat $\%$. A greater average and working day AEE resulted in decrease of BMI, visceral fat rating, body fat $\%$ and fat $\%$ in all segments, while greater days' off AEE - to body and left leg fat $\%$ decrease.

Also, females with lesser inactive and sitting time a working day had lower visceral fat rating, body and leg fat $\%$. The duration of light, moderate and heavy activities did not have any influence on body composition for them. Women with higher average and working days' AEE had lower visceral fat rating, body, trunk and leg fat \%.

Fat utilization for muscle energy supply depends on duration and intensity of PA. Moderate intensity activities below $65 \%$ of maximal oxygen uptake use predominantly fats as a fuel [1]. Short time exercises use mostly intramuscular triacylglycerol, while activities longer than 90-120 min increase the importance of extramuscular fat delivery for energy production in working muscles [29] that might decrease total and segmental body fat $\%$ as well visceral fat rating. Similar influence of exercise on visceral fat is observed also in other studies [21,28].

Moderate and vigorous exercises usually involve greater activation of leg muscles, that leads to local temperature increase in the extremity that stimulates the local fat oxidation [32]. Additionally, increased work of the muscle stimulates enlargement of muscle mass [23]. Both fat oxidation increases intramuscularly and locally in extremity together with muscle hypertrophy might lead to the extremity becoming leaner as observed in our study.

Activities with the MET 1.0-2.9 include mostly sleeping time and activities in sitting position in which there are no or minor leg activities. Longer inactive and sitting time and duration of light activity a working day reverse positive effects of exercise and lead to relatively less muscle mass and more fat mass in them. In other studies, it was found, that sedentary individuals were more likely to gain more body fat and less fat free mass than active individuals when they gained weight [17].

Inverse relationship of average and working day AEE with fat $\%$ in arms observed only in males might be related with relatively more arm exercises during the work and extra-occupational activities e.g. weight lifting.

In both genders, there was no association of duration of inactivity, light, moderate and heavy activities in days off with the body composition 
parameters. Physical activity strategy for the WHO European Region 2016-2025 recommends that adults should undertake at least 150 minutes of moderate-intensity aerobic physical activity each week. The existing recommendations emphasize the health benefits of moderate-intensity activities and that the recommended levels can be accumulated in relatively short bouts of activity at a time [31]. Results of the present study indicate that working day PA additionally to that in day off is necessary to change a body composition.

It is known that contribution of lipids to energy production in women is higher than for man $[4,27]$, but women also normally have higher fat $\%$ in the body [11]. In such conditions even more intense lipolysis triggered during exercise could change body fat $\%$ lesser as for males. This may explain lesser associations between PA and body composition observed in our study.

Also, association of PA and segmental fat $\%$ was less pronounced for women. Women have more fat stored in the gluteo-femoral region [7], which according the BIA is added partially to trunk and leg regions. Changes in the total fat mass in the gluteo-femoral region gives minor effect on body composition in trunk. Men have more storage of abdominal and higher located visceral fat [7], which is included in trunk fat measurement. Additionally, observed visceral fat decrease due to exercise was larger in males [28]. This might lead to the observed negative associations of duration of moderate physical activities with visceral fat rating and that of heavy physical activities with trunk fat $\%$ only in males.

The strength of our study is that PA in healthy adults was evaluated by the combined HR and motion sensor Actiheart, which allows more precise activity data collection than questionnaires or simple motion sensors. The duration of daily moderate and vigorous activities was analysed separately, and their impact on PAL was determined. The effect of inactive and sitting time and duration of PA with different intensities on the body composition, including segmental body composition, parameters was studied.

More day or whole-week PA objective registration is advised for weekly data evaluation instead of the prediction of weekly physical activity from a 3-day recording. This study did not include obese people, thus further studies are needed to describe more precisely the pattern of PA and strength of effect on body composition parameters in this group.

In conclusion, the present study demonstrates that healthy adult men are more engaged in vigorous activities in total than women are, and their PA on working days exceeds that of women. Although men do not have a different PA pattern on working days and days off, females tend to be more active on days off. A distinctive PA pattern on working days and days off allows 
males to be active during a proportionally greater period of the week during working days - and to spend a relatively greater amount of energy and be more frequently qualified as highly active than females. In addition to moderate-intensity activities, which are the primary determinant of PAL in both genders, vigorous activities have a greater (albeit small) influence on males than females. Inverse association of average AEE with total fat, segmental and visceral fat is common in both genders, whereas negative correlation between duration of moderate and vigorous MET minutes and segmental fat is present only in males. These findings might be used for the development of future interventions to promote physical activity with the aim to improve the body weight management.

\section{REFERENCES}

1. Achten J, Gleeson M, Jeukendrup AE. (2002) Determination of the exercise intensity that elicits maximal fat oxidation. Med Sci Sports Exerc, 34: 92-97. https://doi.org/10.1097/00005768-200201000-00015

2. Brage S, Brage N, Ekelund U, Luan Ja, Franks PW, Froberg K, Wareham NJ. (2006) Effect of combined movement and heart rate monitor placement on physical activity estimates during treadmill locomotion and free-living. Eur J Appl Physiol, 96: 517-524. https://doi.org/10.1007/s00421-005-0112-6

3. Brage S, Brage N, Franks PW, Ekelund U, Wareham NJ. (2005) Reliability and validity of the combined heart rate and movement sensor Actiheart. Eur J Clin Nutr, 59: 561-570. https://doi.org/10.1038/sj.ejcn.1602118

4. Dasilva SG, Guidetti L, Buzzachera CF, Elsangedy HM, Krinski K, De Campos W, Goss FL, Baldari C. (2011) Gender-based differences in substrate use during exercise at a self-selected pace. J Strength Cond Res, 25: 2544-2551.

https://doi.org/10.1519/JSC.0b013e3181fb4962

5. Dehghan M, Merchant AT. (2008) Is bioelectrical impedance accurate for use in large epidemiological studies? Nutr J, 7: 26.

https://doi.org/10.1186/1475-2891-7-26

6. Del Duca GF, Nahas MV, de Sousa TF, Mota J, Hallal PC, Peres KG. (2013) Clustering of physical inactivity in leisure, work, commuting and household domains among Brazilian adults. Public Health, 127: 530-537.

https://doi.org/10.1016/j.puhe.2013.02.013

7. Demerath EW, Sun SS, Rogers N, Lee M, Reed D, Choh AC, Couch W, Czerwinski SA, Chumlea WC, Siervogel RM, Towne B. (2007) Anatomical Patterning of Visceral Adipose Tissue: Race, Sex, and Age Variation. Obesity (Silver Spring, Md), 15: 2984-2993. https://doi.org/10.1038/oby.2007.356

8. El Ansari W, Suominen S, Draper S. (2017) Correlates of Achieving the Guidelines of Four Forms of Physical Activity, and the Relationship between Guidelines 
Achievement and Academic Performance: Undergraduate Students in Finland. Cent Eur J Public Health, 25: 87-95. https://doi.org/10.21101/cejph.a4387

9. FAO. Human energy requirements, Report of a Joint FAO/WHO/UNU Expert Consultation. http://www.fao.org.: 2004.

10. Fletcher GF, Landolfo C, Niebauer J, Ozemek C, Arena R, Lavie CJ. (2018) Promoting physical activity and exercise: JACC Health Promotion Series. J Am Coll Cardiol, 72: 3053-3070. https://doi.org/10.1016/j.jacc.2018.10.025

11. Gallagher D, Heymsfield SB, Heo M, Jebb SA, Murgatroyd PR, Sakamoto Y. (2000) Healthy percentage body fat ranges: an approach for developing guidelines based on body mass index. Am J Clin Nutr 72: 694-701. https://doi.org/10.1093/ajcn/72.3.694

12. Grundy SM. (2016) Metabolic syndrome update. Trends Cardiovasc Med, 26: 364-373. https://doi.org/10.1016/j.tcm.2015.10.004

13. Heymsfield S. (2004) Tanita Institute Contract Study. Algorithm development for estimating visceral fat rating. Columbia University College of Physicians and Surgeons., 2004.

14. Kim J, Tanabe K, Yokoyama N, Zempo H, Kuno S. (2013) Objectively measured light-intensity lifestyle activity and sedentary time are independently associated with metabolic syndrome: a cross-sectional study of Japanese adults. Int J Behavl Nutr Phys Act, 10: 30. https://doi.org/10.1186/1479-5868-10-30

15. Kohl HW, Craig CL, Lambert EV, Inoue S, Alkandari JR, Leetongin G, Kahlmeier S. (2012) The pandemic of physical inactivity: global action for public health. Lancet, 380: 294-305. https://doi.org/10.1016/S0140-6736(12)60898-8

16. Kyle UG, Bosaeus I, De Lorenzo AD, Deurenberg P, Elia M, Gómez JM, Heitmann BL, Kent-Smith L, Melchior J-C, Pirlich M, Scharfetter H, Schols AMWJ, Pichard C. (2004) Bioelectrical impedance analysis-part I: review of principles and methods. Clin Nutr, 23: 1226-1243.

https://doi.org/10.1016/j.clnu.2004.06.004

17. Kyle UG, Zhang FF, Morabia A, Pichard C. (2006) Longitudinal study of body composition changes associated with weight change and physical activity. Nutrition, 22: 1103-1111. https://doi.org/10.1016/j.nut.2006.08.003

18. Lee IM, Shiroma EJ, Lobelo F, Puska P, Blair SN, Katzmarzyk PT. (2012) Effect of physical inactivity on major non-communicable diseases worldwide: an analysis of burden of disease and life expectancy. Lancet, 380: 219-229.

https://doi.org/10.1016/S0140-6736(12)61031-9

19. Livingstone MB, Robson PJ, McCarthy S, Kiely M, Harrington K, Browne P, Galvin M, Wareham NJ, Rennie KL. (2001) Physical activity patterns in a nationally representative sample of adults in Ireland. Public Health Nutr, 4: 1107-1116. https://doi.org/10.1079/PHN2001192

20. Löllgen H, Böckenhoff A and Knapp G. (2009) Physical activity and all-cause mortality: an updated meta-analysis with different intensity categories. Int J Sports Med, 30: 213-224. https://doi.org/10.1055/s-0028-1128150 
21. Maillard F, Pereira B and Boisseau N. (2018) Effect of high-intensity interval training on total, abdominal and visceral fat mass: A meta-analysis. Sports Med, 48: 269-288. https://doi.org/10.1007/s40279-017-0807-y

22. Mansoubi M, Pearson N, Clemes SA, Biddle SJH, Bodicoat DH, Tolfrey K, Edwardson CL, Yates T. (2015) Energy expenditure during common sitting and standing tasks: examining the 1.5 MET definition of sedentary behaviour. BMC Public Health, 15: 516. https://doi.org/10.1186/s12889-015-1851-x

23. Ozaki H, Abe T, Mikesky AE, Sakamoto A, Machida S, Naito H. (2015) Physiological stimuli necessary for muscle hypertrophy. J Phys Fit Sports Med, 4: 43-51. https://doi.org/10.7600/jpfsm.4.43

24. Santos DA, Silva AM, Matias CN, Magalhães JP, Fields DA, Minderico CS, Ekelund U, Sardinha LB. (2014) Validity of a combined heart rate and motion sensor for the measurement of free-living energy expenditure in very active individuals. J Sci Med Sport, 17: 387-393.

https://doi.org/10.1016/j.jsams.2013.09.006

25. Schwaneberg T, Weymar F, Ulbricht S, Dörr M, Hoffmann W, van den Berg N. (2017) Relationship between objectively measured intensity of physical activity and self-reported enjoyment of physical activity. Prev Med Rep, 7: 162-168. https://doi.org/10.1016/j.pmedr.2017.06.004

26. Slentz CA, Duscha BD, Johnson JL, Ketchum K, Aiken LB, Samsa GP, Houmard JA, Bales CW, Kraus WE. (2004) Effects of the amount of exercise on body weight, body composition, and measures of central obesity: Strride-a randomized controlled study. Arch Intern Med, 164: 31-39.

https://doi.org/10.1001/archinte.164.1.31

27. Venables MC, Achten J and Jeukendrup AE. (2005) Determinants of fat oxidation during exercise in healthy men and women: a cross-sectional study. J Appl Physiol, 98: 160-167. https://doi.org/10.1152/japplphysiol.00662.2003

28. Verheggen RJ, Maessen MF, Green DJ, Hermus AR, Hopman MT, Thijssen DH. (2016) A systematic review and meta-analysis on the effects of exercise training versus hypocaloric diet: distinct effects on body weight and visceral adipose tissue. Obes Rev, 17: 664-690. https://doi.org/10.1111/obr.12406

29. Watt MJ, Heigenhauser GJF, Dyck DJ, Spriet LL. (2002) Intramuscular triacylglycerol, glycogen and acetyl group metabolism during $4 \mathrm{~h}$ of moderate exercise in man. J Physiol, 541: 969-978. https://doi.org/10.1113/jphysiol.2002.018820

30. WHO. Global Recommendations on Physical Activity for Health. Geneva: World Health Organization, 2010.

31. WHO. Physical activity strategy for the WHO European Region 2016-2025. 2015.

32. Zoladz JA, Koziel A, Broniarek I, Woyda-Ploszczyca AM, Ogrodna K, Majerczak J, Celichowski J, Szkutnik Z, Jarmuszkiewicz W. (2017) Effect of temperature on fatty acid metabolism in skeletal muscle mitochondria of untrained and endurance-trained rats. PLoS ONE 12: e0189456.

https://doi.org/10.1371/journal.pone.0189456 
74 | R Lagzdina, M Rumaka

\section{Correspondence to:}

Rudìte Lagzdiña

Department of Human Physiology and Biochemistry

Rīga Stradiňš University

Dzirciema 16, Riga, LV-1007, Latvia

E-mail: rudite.lagzdina@rsu.lv

Phone (+371) 67061548 